\title{
Global controls on the distribution of nickel and its isotopes in the oceans
}

SETH G. JOHN ${ }^{1}$, SHUN-CHUNG YANG ${ }^{1}$, XIAOPENG BIAN ${ }^{1}$, RACHEL KELlY ${ }^{1}$, DAVID A. HUTCHINS ${ }^{1}$, FEIXUE Fu ${ }^{1}$, HeNGDi LIANG $^{1}$, BenOIT PASQUIER ${ }^{1}$, EMILY SEELEN ${ }^{1}$

${ }^{1}$ University of Southern California, sethjohn@usc.edu, shunchuy@usc.edu, xiaopenb@usc.edu,kellyrl@usc.edu, dahutch@usc.edu,ffu@usc.edu,hengdili@usc.edu, bp_358@usc.edu, seelen@usc.edu.

Nickel appears to be an important micronutrient for phytoplankton living in the modern oceans, based on the known use of $\mathrm{Ni}$ as a cofactor for biologically important enzymes such as superoxide dismutase and urease. It also has a 'nutrient-type' global distribution, whereby $\mathrm{Ni}$ is depleted in the surface ocean and increases between the Atlantic and Pacific in deep waters. Yet, many questions remain about the biological cycling of Ni in the oceans. Particularly, there is uncertainty about the mechanisms by which $\mathrm{Ni}$ is maintained at concentrations which never fall much below $2 \mathrm{nM}$ in oligotrophic gyres, and whether $\mathrm{Ni}$ could have been a limiting nutrient in the past oceans.

Using a combination of experiments, observations, and modeling, we propose a new comprehensive model of $\mathrm{Ni}$ and $\mathrm{Ni}$ isotope $\left(\delta^{60} \mathrm{Ni}\right)$ cycling in the oceans. We find that two models are broadly consistent with oligotrophic gyre $\mathrm{Ni}$ concentrations, either there is a pool of $\sim 2 \mathrm{nM} \mathrm{Ni}$ which is not biologically available, or the biological uptake of $\mathrm{Ni}$ from upwelling waters until macronutrients are depleted, leaving about $2 \mathrm{nM}$ residual Ni. However, targeted modeling studies of $\mathrm{Ni}$ and $\delta^{60} \mathrm{Ni}$ distributions in the North Pacific, as well as experiments on Ni bioavailability, show no evidence of an inert Ni pool, thus favoring the second model.

The amount of $\mathrm{Ni}$ present in oligotrophic gyres is therefore highly dependent on the relative uptake rates of $\mathrm{Ni}$ and macronutrients in upwelling regions, represented by the parameter $\beta$. Observed $\beta$ for modern Southern Ocean diatoms is consistent with the model-predicted $\beta$. However, a survey of $\beta$ values reported for cultured and natural phytoplankton shows great variability in this parameter, depending on species and growth conditions. Thus, oligotrophic gyre $\mathrm{Ni}$ concentrations may be highly dependent on the exact species composition and growth conditions in the Southern Ocean and other upwelling regions. This suggests that $\mathrm{Ni}$ concentration variability in the past surface ocean may be much greater than previously considered, and that $\mathrm{Ni}$ 'famines' in the past ocean may have been frequent. 